\title{
MOHSEN FOROUGHI (1907-1983): THOUGHTS AND SUSTAINABILITY IN THE WORKS OF AN IRANIAN MODERNIST ARCHITECT
}

\author{
Ahmad Moghaddasi ${ }^{1 *}$, Mohammad Hossein Moghaddasi ${ }^{2}$, Hosein Kalantari Khalilabad ${ }^{3}$ \\ ${ }^{1}$ University of Art \\ Sakhai St., 56, Tehran, Iran \\ ${ }^{2}$ Russian State University A.N. Kosygin \\ Sadovnicheskaya st., 33, Moscow, Russia \\ ${ }^{3}$ Academic Center for Education, Culture and Research \\ Tehran, Iran \\ *Corresponding author: ahmad.moghaddasi@gmail.com
}

\begin{abstract}
Introduction: Mohsen Foroughi was one of the first-generation Iranian modernist architects who joined Iranian architecture in the 1940s. His knowledge of architecture obtained in one of the most important French architectural schools-École des Beaux-Arts-allowed him to create valuable works by combining the spirit of Iranian architecture with modern values. His interest in education led to the establishment of the foundations of architecture teaching in Iran, based on the lessons taught in Europe. Purpose of the study: The article addresses the works of Mohsen Foroughi, combining modern architecture with the vernacular Iranian architecture. His most significant works include the building of the Senate, the Department of Law at the University of Tehran, the National Bank of Tehran's Bazaar, and the Saadi Tomb in Shiraz. The article looks at the development of intellectual flows of the time that evolved into social relationships. Methods: In the course of the study, we use descriptive analysis and analysis of library resources. Results: The main characteristics of Foroughi's work are balance, symmetry, and application of the main elements of traditional Iranian architecture. By better understanding of his works, architects can be more successful in creating today's architectural projects.
\end{abstract}

\section{Keywords}

Mohsen Foroughi, contemporary architecture, Iranian architecture, Saadi Tomb, National Bank, modernism.

\section{Introduction}

Mohsen Foroughi was the son of famous statesman Mohammad-Ali Foroughi. He was sent to France to study abroad in 1926, where he chose the École des Beaux-Arts, specializing in architecture. He graduated in 1937, coming first in his class and winning the prize for the best diploma (Gillet, 1983), and came back to Iran in the same year and taught at the various Departments of the University of Tehran, including the Department of Engineering. He was instrumental, along with André Godard, Roland Dubrul, and Maxime Siroux, in establishing the University of Tehran's College of Fine Arts in 1940 and was one of its initial professors, eventually succeeding Godard as its dean (Marefat and Frye, 2000).

Foroughi was the architect of numerous public buildings. He also advised and carried out several restoration and building projects for the National Monuments Council of Iran, including designs for the mausoleums of Sa'dī in Shiraz (Figure 1) and Bābā Tāâner in Hamadān. Foroughi collaborated with Godard, Siroux, and Dubrul on the design of the master plan for the University of Tehran and its associated buildings, including the Department of Law and Political Science (Marefat, 1988, Marefat and Frye, 2000).
Mohsen Foroughi is one of the most influential architects of public buildings, although the design of several villas is also featured in his repertoire. He is one of the founders of the academic system of architectural education in Iran along with Godard. This architect is considered as one of the most influential people in the Iranian modern architecture movement. Most of Foroughi's architectural works have led to the creation of sustainable architecture, which, of course, should all be included in the heritage of contemporary architecture.

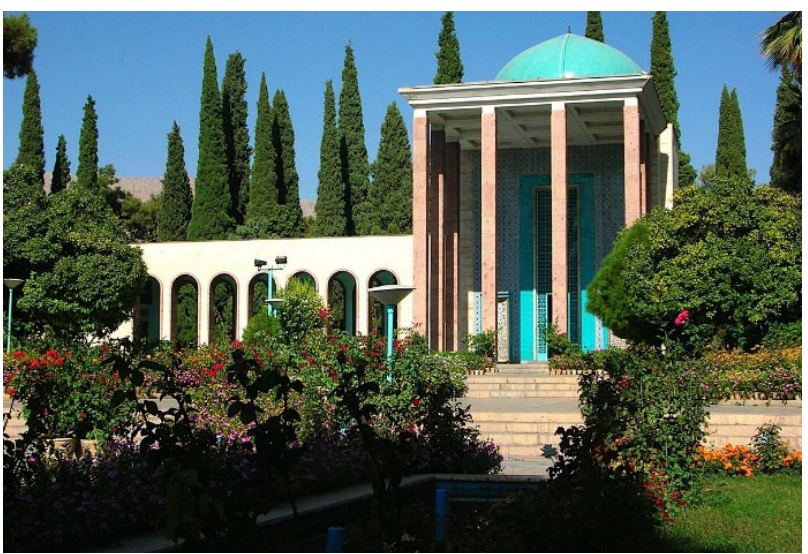

Figure 1. Saadi Tomb, Shiraz, Iran (Ph.: Omid Hatami) 


\section{Methods}

In line with studying the cultural fundamentals in Foroughi's architectural works, we shall first analyze the physical and structural elements in Iranian architecture by using a descriptive and analytical approach. This method was used before in a similar research by M. Shahidi (Shahidi et al., 2010).

The fundamentals might have changed throughout the history of Iranian architecture; however, in terms of context, they can be used as sets of indicators by architects (Moghaddasi and Zamanifard, 2013).

\section{Research objectives}

\section{Foroughi's work principles}

Mohsen Foroughi was a modernist architect who admired Iranian culture and history. $\mathrm{He}$ stated that the formal representation of history in the works of his young colleagues is superficial and believed that the relations between buildings can be divided into two following groups: evident and metaphorical relations. In Foroughi's opinion, an example of the evident relation is the relation between the Sassanid and Achaemenid buildings with Sassanid architecture remodeling Achaemenid architecture (Banimasoud, 2009).

The metaphorical relation is when architects employ the best materials of their time by respecting vernacular architecture.

Foroughi considered climate and materials to be the most important elements. He believed that the major differences in architectural styles are due to the variation of materials and the approach of architects to them. Foroughi also recognized the climate of Iran as one of the most essential factors affecting architectural design (Banimasoud, 2009).

Some of his masterpieces include the colleges of the University of Tehran (1938), the National Bank of Isfahan (1941), the National Bank of Bazaar (1945), the Ministry of Finance, the Agricultural Bank (1953), the building of the Senate (Figure 2), and the House of Iran in Paris (in collaboration with Ghiai, Zafar and others in 1962).

Foroughi had a semi-historical look at the architecture of public buildings before 1951. Therefore, the use of raised columns and turquoise tile in the facades of buildings, the focus on the

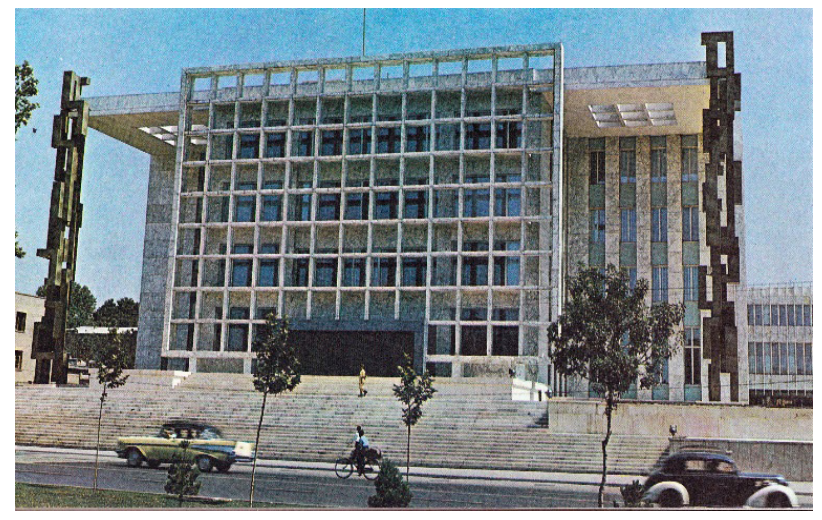

Figure 2. Senate Building, Tehran, Iran (source: wikipedia.org) entrance, and the utilization of concrete or stone can be considered the effects of Foroughi's works on the Iranian architecture of that period.

Foroughi's works can be classified into three categories depending on the period and style: national neoclassical style, modern international style, and modern progressive style (Sabatsani, 2014).

The most important point about Foroughi's works is that so far, no comprehensive research has been performed in their regard.

\section{Founder of the modern Iranian architecture}

Foroughi presented us with the idea of a new architecture and taught us how to use modern technology in architecture. Architecture and technology form and shape ideas, making them visible and tangible. According to Dr. Falamaki, every architectural project belongs to all humankind (Falamaki, 2002).

The authentic Foroughi's architecture overcame all obstacles of the past and was spread by Foroughi himself and others. To critique his works, we must first understand his thoughts. According to Mohammad Reza Haeri: "An architect cannot be defined by a project, and a project cannot only represent an architect. Interpreting the functions of plans and maps is not an architectural critique. We should get acquainted with Foroughi first, and then look at his works." (Bavar, 2002).

\subsection{Roots of modernism among Iranian} intellectuals

In the face of past architectural traditions and the late industrial revolution in Iran, we can consider the Constitutional Revolution as the turning point in Iranian architecture, after which great changes gradually began to emerge. Although it did not succeed completely, the Constitutional Revolution paved the way for the future, laid new social foundations, and built new relationships. Despite the fact that the effects of this profound transformation and disruption in architecture were not immediate, they moved things forward in an effort to put an end to the dependence on the past political and governmental systems. Politicians familiar with the science and industry came to the forefront, and with passion and enthusiasm, they tried to bring some features of Western industrial civilization to Iran. The very beginning of the transformation was a new way of life, which directly affected Iranian architecture. In the first decade of the new century, with the start of the Pahlavi dynasty, extensive construction began, which obviously cannot be commensurate with that of the past centuries in terms of speed. The actual beginning of architectural developments in Iran coincides with the beginning of the new century (1922 (1300 HS)), especially since at the same time, the country witnessed fundamental political and governmental changes, which were the result of the socio-political transformation. It started with the beginning of the Constitutionalist Movement, 
with the signing of the constitutional order and the formation of the National Assembly, producing a positive political outcome. The government came to the fore and created a context for the coup of 1921 (1299 HS) (Bavar, 2002).

The changes that took place in Iranian society and the way of life opened the way for transformation in architecture and the spread of cities. With better overseas communication, recognition and the possibility of using technical and structural improvements in architectural activities were provided. Since architecture has always evolved in line with social, political, and economic changes, we need to determine the timing and causes of corresponding changes in architecture.

Those who analyze architecture should have a close look at the thought of the past. The problem that is on our minds today is how our century was formed and how the roots of modern thought were replaced in the hearts of people. To do that, we need to consider the milestones of the past. Returning to the past is not just a matter of examining its eventsit needs to be felt and touched so that it can be transformed. The factors that brought about these behavioral, national, and political changes should also be analyzed along with their impact on each other. "One needs to know which of the past events is more important for this age." (Giedion, 1967).

Mohammad Ali Foroughi and Sayyed Hassan Taqizadeh were representatives of the second generation of Iranian intellectuals, and their political activities, along with their academic and cultural activities, were essentially the result of their nationalist, secular, and modernist ideas. Foroughi knew very well that modernism was based on reason, and that the translation of Descartes' theory and the emphasis on the phrase "I think therefore I am" were a way to bring the concept of rationality to the depths of Iranian society. Individuals such as Foroughi longing for public progress and the usefulness of nations can be found among Iranian intellectuals and reformists: Taghi Arani, Mohammad Ali Jamalzadeh, Sayyed Hassan Taqizadeh, Morteza Moshfegh Kazemi, Mohammad Asemi, Hossein Kazemzadeh Iranshahr, etc. Publications of Kaveh, Iranshahr, Farhangestan, scientific and artistic works on such topics as public education, women's rights, war against prejudice, translations of European books, and the adoption of particular principles and conventions show that the European civilization is reforming Iran. The first issue of Nameh-ye Farhangestan (Academy's Letter) states: "What do we want? We want Iran to awaken from its centuries-long hibernation". According to many scholars of that period, this awakening was due to tolerance to the Western civilization through the complete acquisition of the foreign civilization conditional on the preservation of the Persian language. That tolerance resulted in a set of writings and translations, the most famous of which are the translation of Descartes' work, the natural philosophy of Ibn Sina, The Course of Wisdom in Europe by Mohammad Ali Foroughi, translations of Kafka by Hedayat, translations of Chekhov by Bozorg Alavi, the short story Persian is Sugar written by Mohammad Ali Jamalzadeh, The Horrible Tehran by Morteza Moshfegh Kazemi, and the play Ja'far Khan Returns From Abroad by Hassan Moghaddam, represent the encounter of Iranian second-generation intellectuals with modernity (Jahanbegloo, 2001).

In the Iranian society, both the contemporary intellectuals and the interim government wanted Iran to move towards global progress, face the advanced world with its technical, artistic. and constructive innovations. All the modern and advanced Iranians wanted Iran to wake up from a silent, motionless sleep. The Iranians, who were moving forward, sought for rationalism, development in such areas as science, technology, and agriculture. They aimed to bring modern technology, resource management, as well as waterways, airways, and motorways, to Iran. They also wanted to get along with other advanced countries. Intellectuals were essential and helpful for both the government and society.

Iran was a backward country: it was lagging behind everything in all fields. Therefore, seeking to escape backwardness, the uninhibited society needed a new path to the future.

The set of issues that Iran faced in the late Qajar period was the result of years of sluggish agriculture affecting family livelihood. However, the result of this backwardness in Iran has not yet been determined definitively.

"For this reason, Iranians as a product of the Iranian civilization with its views and values, are neither completely traditional nor absolutely modern. They look both to the modern world and the world of traditions." (Jahanbegloo, 2001).

In the first and second decades of the new century, with the coming of the new regime, construction started in various fields (construction of roads and other basic facilities, government buildings, schools, radio and telecommunication systems, railways, bridges, airports, industrial plants, etc.)the country urgently needed to develop industry, economics, and construction, and engage in global politics. The era was very active and dynamic. A series of tensions and trends remaining from the past continued to pave the way for the future. There is no doubt that our culture is based on the legacy of the past generations, and the systematic process of socio-political and economic changes maintains. Trying to move quicker, our society was bound to create new starting points and pursue another path (Giedion, 1967).

This was how Mohsen Foroughi took the path of the political and cultural regime of the time. It was the road to modernization and modernity, the way 
to confront the advances of the modern world in art, architecture, and technology.

Why did not Foroughi use Sasanian architecture or motifs and architectural forms of Achaemenid art in his works like Godard?

Neither Foroughi, nor the other architects such as Abkaar, Vartaan, and Gurkian went back to the architecture of the past. Instead, they tried to move forward and create works that would not only introduce spatial innovations and new building techniques but also confront the architectural advances of the Western world. Foroughi did not use traditions as a model in his modern architecture since the modern movement had occupied his conscience and thought. This meant a complete awareness of the beginning of a new era, which Foroughi was trying to present by creating new architectural spaces. Foroughi deliberately stepped in and laid the foundations of modern architecture in Iran.

As mentioned earlier, modern thought became common in Iran before the Constitutional Revolution. Before the Constitutional Revolution, Abbas Mirza tried to modernize the Iranian Army. Amir Kabir and Sepahsalar made efforts to familiarize Iranians with new science and education programs. With the start of the new era, activities aimed at the modernization of Iran were carried out in two ways. On the one hand, Iranian students were sent to Europe to study science and gain knowledge, and on the other hand, European engineers and experts were brought to Iran to set up schools and educational centers run by the government. "The reformists of that period did not believe that the general public, or traditional scholars and systems, could implement their ideas. For example, Seyyed Jamal al-Din Assadabadi thought that reliance on religious power had not led to any civilized progress in Iran. However, such progress could be achieved through the recognition of the technological advancements of the West." (Jahanbegloo, 2001). Thus, with the coming of the Pahlavi government, the country's political life changed considerably. In the first decade of 1300 HS, groups of young people were sent abroad to study. Among them, Foroughi, Vartaan, and Abkaar can be mentioned.

After returning, they were engaged in intellectual activities. So, who was Foroughi and what role he played in the emergence of modern architecture in Iran?

Foroughi, a son of Mohammad Ali Foroughi (Zak"a al-Molk), grew up in a political and cultural family. Between 1929 and 1935, he completed his university studies in architecture at the School of Fine Arts in Paris (École des Beaux-Arts) and then returned to Iran. At the time, the country was expanding, modernizing virtually all social, cultural, structural, and industrial aspects. So, there were plenty of opportunities to advance expertise.
In post-Qajar Iran, government planners sought to find technological solutions, implementing a gradual shift in construction to specific activities and innovations regarding education, intelligence, and social culture. They knew that modern educational and specialized institutions had originated from the development of cultures, higher education, and research. In general, it led to cultural changes that can be the only correct response when dealing with the slow process and the same technology of the past in architecture and civil engineering.

It seems that the basic principles of the Iranian modernization plan accounting for educational and cultural advancements can shape all construction activities. Besides, with account for the quality of space, construction activities open up in terms of environmental creativity and social reality, by eliminating various forms of imposed life style. Educational advancements can help solve problems and, contrary to what is available, they are a robust and predictable force that in the first two decades of $1300 \mathrm{HS}$, the spirit of times in the field of culture and education, had quite a positive effect considered the essential and necessary means in the development of society (Wilber, 2003). It was also believed that the primary focus of the new organization of education should be not a service for all but its further development in relation to the transformation, as a social framework of perceptual and conceptual presence.

The government, the intellectuals, and those responsible knew that modern educational and specialized institutions could form the entire required structure. With regard to the advancements in technology and construction, it will help overcome social backwardness and move forward confidently, facilitating the expansion of all manufacturing sectors, as a result of the progress of social civilization.

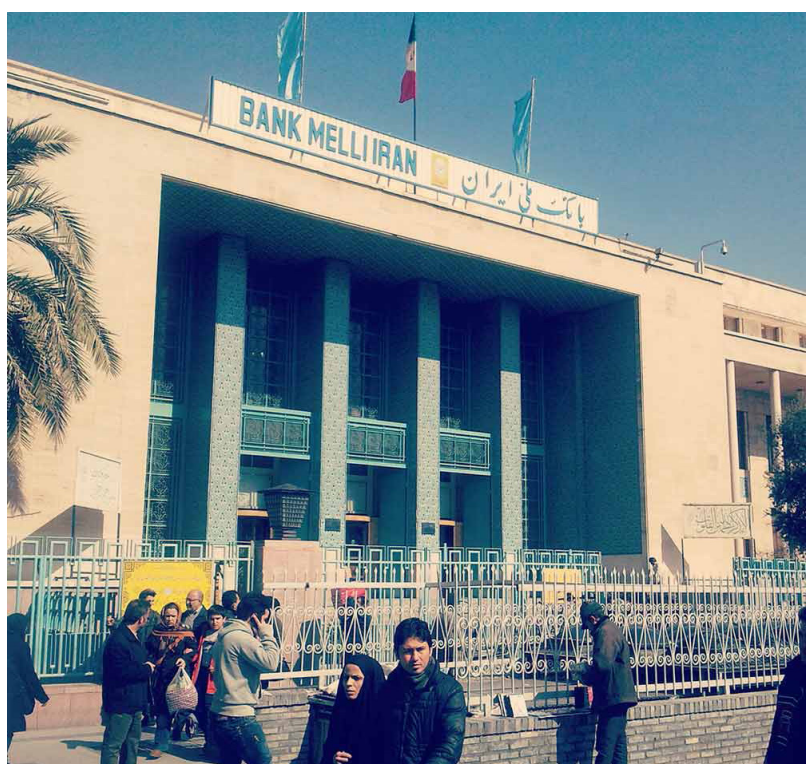

Figure 3. National Bank of Bazaar (exterior view), Tehran, Iran (Photo By: Saeb Kefayati) 


\subsection{Emergence of a modernist architect}

Under these conditions, Foroughi appears on the scene.

With the political backing inherited from Zaka alMolk (his father) and due to his father's prominence in political and cultural activities of the Iranian political community, Foroughi found himself in a prefabricated atmosphere and quickly entered the field of cultural and political action.

Foroughi's activities can be divided into two categories: activities in the field of politics; activities in the field of engineering.

As for politics, after returning to Iran, Foroughi was elected as a representative in the National Assembly. Later he became a Senate representative.

His career in engineering developed in three directions: cultural; archaeological and artistic; architectural.

Foroughi was the second and the most important director of the College of Fine Arts in the University of Tehran after Andre Godard, the founder and chairman of the College. He had a distinct, calm, and solemn character. He talked slowly and treated students with respect, thus, he was much respected himself. His colleagues included Sadeq Hedayat, the Director of the College library and translator of training programs from the École des Beaux-Arts of Paris, Mr. Ghahrampanpur, the College Secretary, Mr. Moghadam who taught art history, and Eng. Sanei, Eng. Sayhoun, Eng. Farman Farmaeian, and Eng. Ghiai.

As for architecture, Foroughi's works can be viewed as the systematic architecture of the first Pahlavi period. His buildings are more than objects in a national neoclassical style and, while large-scale and bulky, they are distinguished by a particular elegance. Foroughi did not return to any forms of the Iranian architecture of the past but tried to use more advanced techniques of the West and make them perfect in his buildings. He believed that there was "a massive revolution in politics and thought, which produced outstanding works that could be a strong and justified reason for revolutionary events in architecture" (Collins, 1998).

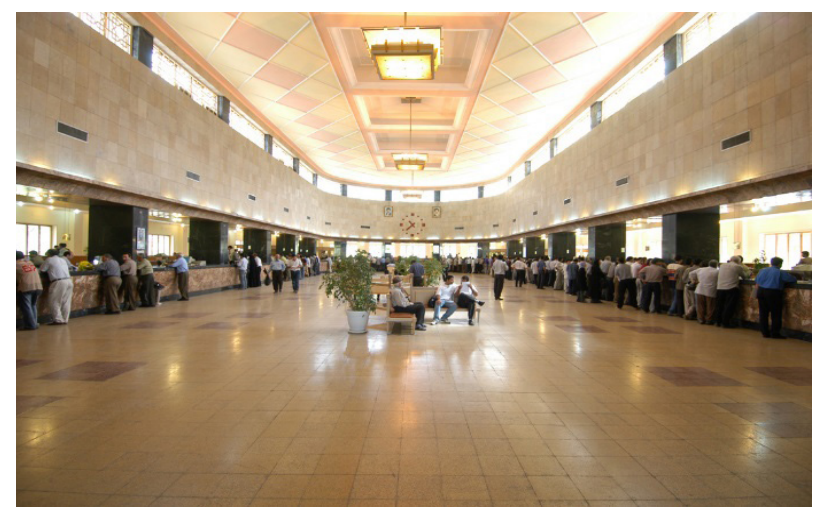

Figure 4. National Bank of Bazaar (interior view), Tehran, Iran (Photo By: Bank Melli Iran's website (National Bank of Iran))
He was trying to create a new contemporary architectural thought that other architects attempted to achieve at the same time in Iran and the West.

Some of his most valuable works employing the most advanced technologies of that time include the Department of Law, University of Tehran (1938) (Zarkesh, 2012), the National Bank of Isfahan (1941), the National Bank of Tehran's Great Bazaar (1944) (Figures 3, 4), and the Agricultural Bank (1953) (currently the Trading Bank of Fayyaz Bakhsh, North Side of Park City). It should be noted that employers of that time were educated, enlightened and civilized people. Among his activities, we can mention participation in the design and implementation of the Senate building in cooperation with Heydar Ghiai and Kayqhobad Zafar. Foroughi believed that "the characteristic feature of modernism is a permanent change, and progress is an essential human action suited to human needs".

Let us take a look at the Isfahan National Bank (Figures 5, 6). "At the corner, from the west side to the south, this rectangular volume of cubes ends with a semi-circular veranda. This veranda provides light to the architectural space, leading the eye to the other side. From the bottom to the top, there are narrow and long columns. They enter into a conflict with the main body, making a huge and heavy volume with a very elegant style." (Bavar, 2001).

Other works of Foroughi include the Dorud railway station, the residential building of $\mathrm{Mr}$. Ghahraman Bakhtiar (northern corner of the Rumi Bridge), his residential home on Pahlavi street, the residential building of Mr. Lak on the Yakhchal street opposite the Qavam House, which has become a park today, the Ministry of Finance, the Saadi Tomb (in collaboration with Ali Sadegh), the Tomb of Reza Shah (in collaboration with Ali Sadegh and Kayqhobad Zafar) (Adle and Hourcade, 1992).

The other joint work of Foroughi and Ghiai is the Maison de l'Iran Building in Paris (1968) (Figure 7).

This project was developed in a general office in Tehran by Claude Parent, André Bloc, Moshen Foroughi, and Heydar Ghiai, Eng. Iraj Ghiai and Eng. Kamran Sepahbodi who contributed to the

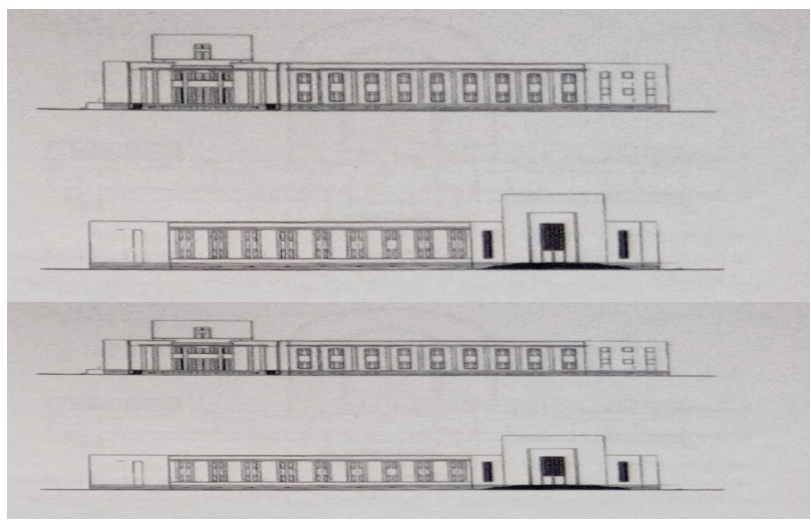

Figure 5. National Bank (architectural sections), Isfahan, Iran (Drawing By: Cyrus Bavar) 
preparation of the plans. The building consists of three metal frameworks with a height of 38 meters, and two lightweight four-story blocks suspended over several meters. The metal stairs interlocking in the block are designed by André Bloc, whose expertise in sculpture made the building prominent.

\section{Results and discussion}

Foroughi was very interested in archeology and had a thorough knowledge of antique items. He had a valuable collection of antiques at his home, specializing in ancient coins and seals, and visiting scholars were always welcomed and assisted in studying his collections. He was a senior adviser to André Godard and Roman Grishman and an expert in visual arts, especially impressionism.

In addition to being fluent in French, Foroughi was familiar with some of the Iranian ancient languages. He had a scientific, artistic, and political personality, and embodied outstanding moral qualities. He was a very humble, good-natured, humorous, communicative, and curious person, aware of the global issues and continuing Iranian traditions. Foroughi resigned from the College of Fine Arts in 1962 due to political conflicts, but his atelier remained there in his name.

Looking at Foroughi's works, we can see that he had special skills in combining the principles of Western modernism with traditional Iranian architecture using two general ways. For instance, in the Senate building, which was directly inspired by the works of the Achaemenid and Sassanid periods, we can find the main architectural elements of that time, such as the Pillar Hall, which is an evident relation. In another group of his works, a metaphorical relation can be observed: Foroughi

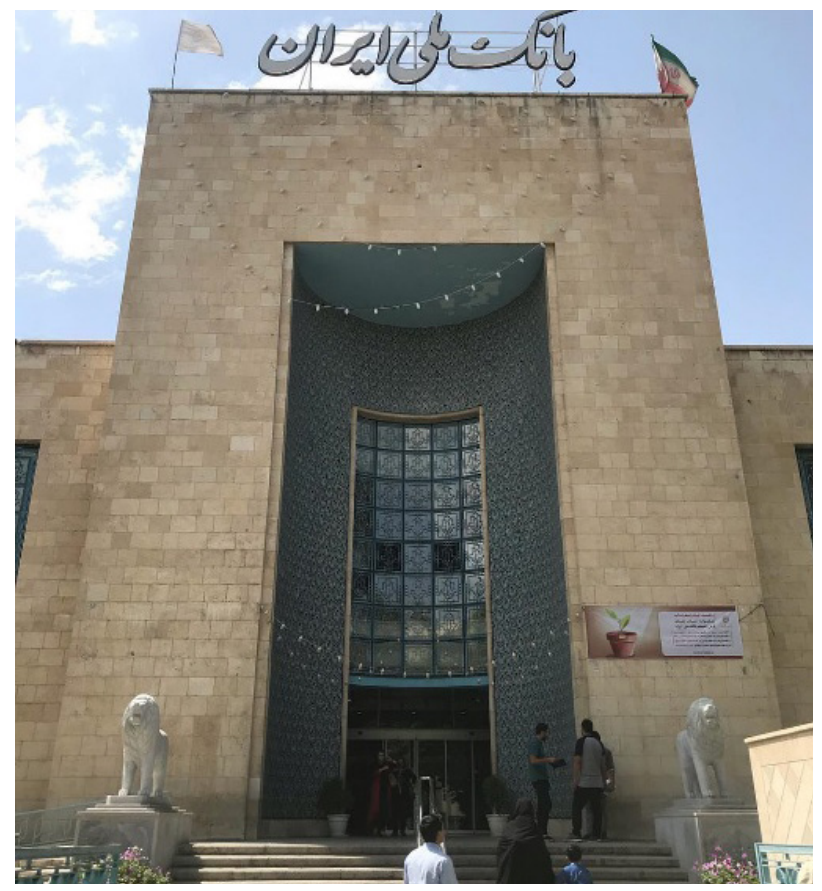

Figure 6. National Bank (entrance view), Isfahan, Iran (source: deskgram.net) used the best materials and techniques of the time while respecting the common principles of Iranian architecture, such as privacy, context-based materials, and climate-friendly design. Contextbased materials were clearly used in all his works both in Iran and France.

The academic principles that Foroughi established in architectural education in Iran can be seen to this day. Before him, architecture was traditionally taught orally, based on the teacherstudent relationship in architecture workshops. After the establishment of the College of Fine Arts, traditional knowledge was combined with new methods of teaching and transformed into a modern form. Foroughi was well aware of the onslaught of contemporary modernism at the time and, using his knowledge and patriotism, prevented damage to the original Iranian architecture. In fact, he transformed modernity in Iranian architecture and defeated modernism in Iran like the previous invasive cultures in Iran (the Arab and the Mongol invasions). While his works represent contemporary Iranian architecture, they also express his spirits and personality traits. The importance of Foroughi's work is so vital that contemporary Iranian architecture can be divided into two categories: before and after him, since his role in educating the architects of the next generation is quite clear.

Foroughi taught us how to think and how to form and shape our age, whether through the creation of modern society or the creation of contemporary spaces. His dignity and balance are seen in all his architectural works: the Department of Law at the University of Tehran, the National Bank of Bazaar, the National Bank of Isfahan.

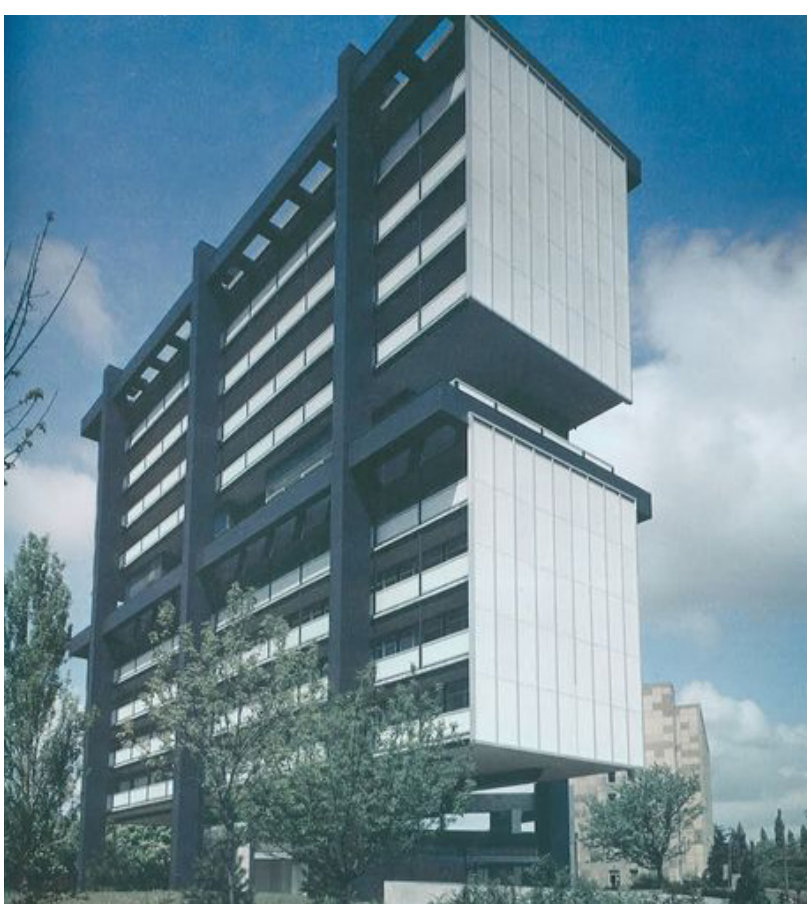

Figure 7. Maison de l'Iran, Paris, France (Hidden Architecture website: http://hiddenarchitecture.net) 


\section{References}

Adle, C. and Hourcade, B. (1992). Téhéran, capitale bicentenaire. Paris, Téhéran: Institut français de recherche en Iran, $386 \mathrm{p}$.

Banimasoud, A. (2009). Contemporary Iranian architecture in struggling between tradition and modernity. Tehran: Honar-e-Memari, $536 \mathrm{p}$.

Bavar, C. (2001). National Bank of Isfahan. Architecture and Culture. Tehran: Office of Cultural Studies, pp. 10-16.

Bavar, C. (2002). Founders of the modern Iranian architecture (Mohsen Foroughi, 1907-1983). Architecture and Urbanism, pp. 24-29.

Collins, P. (1998). Changing ideals in modern architecture, 1750-1950. Montreal: McGill-Queen's University Press, 365 p. Falamaki, M. M. (2002). Origins and theoretical tendencies of architecture. Tehran: Nashr-e-Faza, 409 p.

Giedion, S. (1967). Space, time and architecture: the growth of a new tradition. Cambridge: Harvard University Press, 897 p.

Gillet, G. (1983). Discours de M. Guillaume Gillet, Président. Paris: Institut de France, Académie des Beaux-Arts, 20 p. Jahanbegloo, R. (2001). Rationality and modernity in the writings of Mohammad Ali Foroughi. Iran Nameh, 77, pp. 33-40. Marefat, M. (1988). Building to power: architecture of Tehran 1921-1941. PhD Thesis in Architecture. Cambridge: Massachusetts Institute of Technology.

Marefat, M. and Frye, R. N. (2000). Forūgī, Mohsen. [online] Encyclopaedia Iranica. Available at: http://www.iranicaonline.org/articles/forugi-mohsen [Date accessed 29. 01. 2019].

Moghaddasi, A. and Zamanifard, A. (2013). Paradise on the Earth: Role of water, tree and geometry in the formation of Persian Gardens. Scientific Herald of the Voronezh State University of Architecture \& Civil Engineering, 3, pp. 63-71.

Sabatsani, N. (2014). Investigation of effective factors of Iranian contemporary architecture (1961-1978). Armanshahr Architecture \& Urban Development, 6 (11), pp. 49-60.

Shahidi, M., Bemanian, M. R., Almasifar, N. and Okhovat, H. (2010). A study on cultural and environmental basics at formal elements of persian gardens (before \& after Islam). Asian Culture and History, 2 (2), pp. 133-147. DOI: 10.5539/ ACH.V2N2P133.

Wilber, D. N. (2003). Pahlavi architecture before World War II. Architecture and Culture, pp. 12-15.

Zarkesh, A. (2012). Influence of architecture of governmental and public buildings on private buildings in the Second Pahlavi Era. Bagh-E Nazar, 9 (22), pp. 23-34. 